\title{
Protective effect of Acer mono Max. sap on water immersion restraint stress-induced gastric ulceration
}

\author{
CHUL-HONG PARK ${ }^{1,3^{*}}$, HYUNG-U SON ${ }^{1 *}$, MINSIK SON ${ }^{1,4}$ and SANG-HAN LEE ${ }^{1,2}$ \\ ${ }^{1}$ Department of Food Science and Biotechnology, Graduate School, Kyungpook National University, Daegu 702-701; \\ ${ }^{2}$ Food and Bio-Industry Research Institute, Kyungpook National University, Daegu 702-701, Republic of Korea
}

Received May 25, 2011; Accepted June 20, 2011

DOI: $10.3892 /$ etm.2011.314

\begin{abstract}
Acer mono Max. sap (AmMs) is called 'Gol-Li-Su' or 'Go-Lo-Soe' in Korean, which means 'water beneficial to the bones'. It is reported that the sap contains several types of minerals and sugars. In particular, the calcium concentration of the sap is 36.5 times higher than that of commercial mineral water. Apart from its anti-osteoporosis effect, no reports have addressed the biological activities of AmMs against degenerative diseases. In the present study, we investigated whether AmMs alleviates gastric ulcer-related symptoms in a stress-induced mouse model. To assess the effect of AmMs on gastric ulcer-like symptoms, we carried out a water immersion restraint (WIRE) test and found that AmMs has potential in alleviating gastric ulcers in a concentration-dependent manner. These results indicate that the nutritional factors of the sap mitigate the gastric ulcer-related symptoms caused by stress-induced gastric lesions in mice. AmMs-treated mice exhibited a significant decrease in the ulcer index as compared to those treated with omeprazole or L-arginine. To examine one potential mechanism underlying this effect, we performed
\end{abstract}

Correspondence to: Professor Sang-Han Lee, Department of Food Science and Biotechnology, Graduate School, Kyungpook National University, Daegu 702-701, Republic of Korea

E-mail: sang@knu.ac.kr

Present addresses: ${ }^{3}$ Korea Atomic Energy Research Institute, JeongEup 580-185; ${ }^{4}$ NanoHelix Co., Ltd., Deajeon 305-811, Republic of Korea

\section{${ }^{*}$ Contributed equally}

Abbreviations: AmMs, sap of Acer mono Max.; WIRE, water immersion restraint test; RT-PCR, reverse transcription-polymerase chain reaction; iNOS, inducible nitric oxide synthase; eNOS, endothelial nitric oxide synthase; nNOS, neuronal nitric oxide synthase; cNOS, constitutive nitric oxide synthase; p.o., per oral; i.p., intraperitoneal

Key words: gastric lesion, water immersion restraint stress, inducible nitric oxide synthase, reverse transcription-polymerase chain reaction, sap, Acer mono Max. reverse transcription-polymerase chain reaction to ascertain whether molecular markers were associated with the mitigation of the gastric lesions. Epithelial and/or tissue nitric oxide synthase (NOS) was assessed to determine whether or not the genes were down-regulated dose-dependently by the sap. The levels of these enzymes were found to be lower in the tissue samples treated with AmMs compared with the levels in the control samples. These findings collectively suggest that AmMs significantly protects the gastric mucosa against WIRE stress-induced gastric lesions, at least in part, by alleviating inducible NOS and/or neuronal NOS expression.

\section{Introduction}

Acute gastric mucosal injury is a serious clinical problem worldwide. The symptoms cause severe gastric ulceritis and, with sustained exposure, eventually lead to gastric cancer. Researchers have developed many in vivo gastric lesion models: the water immersion restraint (WIRE) stress model, the indomethacin-induced model and the ethanol-induced model using animals (1). The WIRE model has previously been used to observe various aspects affecting the formation of and recovery from gastric mucosal lesions, including sulphydryls, prostaglandins, growth factors and polyamines (2). WIRE stress-induced gastric lesions have also been used to study the roles of cell death and gastric acid secretion in ulcerogenesis (3).

In general terms, gastric lesions are a disorder of the gastric blockade, which typically protects against cavernous problems caused by hydrogen ions and other toxic substances generated in the lumen (4). One main component of the gastric barrier is gastric microcirculation; a disturbance in gastric mucosal perfusion results in the formation of lesions and ulcers, such as those that present in animal models of ischemic gastric lesions (5). Gastric blood flow is classically controlled by signaling molecules, such as prostaglandins and nitric oxide (NO), which play key roles in sustaining mucosal tissue integrity (6). $\mathrm{NO}$ is produced by nitric oxide synthase in particular, which is generally classified into two categories: i) constitutive nitric oxide synthase (cNOS) and ii) inducible nitric oxide synthase (iNOS). The cNOS isoforms include endothelial nitric oxide synthase (eNOS), which controls vascular homeostasis in endothelial cells, platelets and mesangial cells (7), and neuronal nitric oxide synthase (nNOS), which produces NO to act as a 
neurotransmitter in central and peripheral nerve cells (8). The third isoform, iNOS, is a calcium-independent enzyme which can be found in various human tissues, including immune cells (9). The NOS isoforms have been characterized in the gastrointestinal tract, and NO produced from cNOS and iNOS has been shown to play a key role in the formation of gastric lesions (10).

Many studies have investigated methods for curing and/or preventing gastric lesions with chemically synthesized drugs (11). Recently, it has also been reported that many traditional Asian herbal remedies act on gastrointestinal diseases (12). Acer mono Max. sap (AmMs) has been used in East Asian countries for centuries due to its anti-osteoporosis effects (13); however, traditional East Asian medical literature claims that the sap has potential anti-oxidative and immunomodulatory efects $(14,15)$. Previous in vitro and in vivo studies have confirmed that constituents from AmMs have anti-osteoporosis effects by increasing calcium ion absortion (13), but no prior study has investigated whether or not AmMs has gastroprotective effects.

Therefore, we investigated whether AmMs exhibits protective effects against WIRE stress-induced gastric lesions in mice as well as its effects activated through changes in iNOS/ nNOS and COX-2 mRNA expression, as their expression may be an indicator controlling the status of WIRE-induced gastric ulceration.

\section{Materials and methods}

Chemicals. TRIzol ${ }^{\circledR}$ reagent was purchased from Invitrogen (Carlsbad, CA, USA). L-arginine and omeprazole \{5-methoxy-2-[[(4-methoxy-3,5-dimethyl-2-pyridinyl)methyl] sulfinyl]-1H-benzimidazole; MW, 345.42\} were obtained from Sigma-Aldrich Co. (St. Louis, MO, USA) as positive controls. QA-Agarose and the Maxime RT-PCR PreMix kit were purchased from Qbiogene, Inc. (Irvine, CA, USA) and iNtRON Biotechnology (Sungnam, Korea), respectively. All other chemicals were molecular biology grade.

Preparation and treatment with AmMs. The sap $(1,000 \mathrm{ml})$ of Acer mono Max. was collected from a habitat of Acer mono on Mt. Myun Bong (altitude 550 m), Juk Jang Myun, Pohang, Korea, between February 24 and 25, 2008. The collected AmMs was centrifuged and aseptically filtered using a membrane filter $(0.45 \mu \mathrm{m})$, and then stored at $-70^{\circ} \mathrm{C}$ until it was freeze-dried to obtain a powder. Freeze-drying was carried out using a lyophilizer (Il-Shin BioBase, FMCD series, Seoul, Korea) overnight, and $13.5 \mathrm{~g}$ of powder was finally obtained. The color of the freeze-dried powder was pale white. The voucher specimen was deposited in the Food Enzyme Biotechnology Laboratory, Kyungpook National University, Daegu, Korea. The mineral content (mg/l) showed that the sap contained high amounts of calcium (36.5-fold), potassium (17-fold) and magnesium (4-fold) [(13) and data not shown].

Animal care and experiment. Six-week-old male Balb/c SPF mice, weighing 20-23 g, were purchased from Samtaco Korea (Osan, Korea) and were fed a commercial diet (Purina, Korea) and given water ad libitum. They were housed in an air-conditioned animal room at a temperature of $22 \pm 1^{\circ} \mathrm{C}$ and a humidity of $55 \pm 5 \%$. All procedures were performed in compliance with the rules and in-house guidelines for animal experiments, including ethical care under the guidance of the university committee (16), and the guidelines of the International Association for the Study of Pain Committee for Research and Ethical Issues (17). Animals were allowed to acclimate to the laboratory atmosphere for at least 1 week prior to the experiments. The number of each experimental group was limited to six.

Induction of gastric mucosal lesions. The WIRE stressinduced gastric lesion model was produced as previously described (18). The mice were randomly separated into control (no treatment), L-arginine $(300 \mathrm{mg} / \mathrm{kg})$, omeprazole $(3 \mathrm{mg} /$ $\mathrm{kg}$ ) and AmMs (30 or $150 \mathrm{mg} / \mathrm{kg}$ ) groups (6 mice per group). L-arginine was utilized as a positive control since it exhibits potent protective effects against acute gastric mucosal induction (18). Omeprazole is also well known as an anti-ulcerative worldwide (19). Prior to treatment of the mice, food was withdrawn for $24 \mathrm{~h}$, while water was provided ad libitum. The L-arginine-treated mice $(n=6)$ received one intraperitoneal (i.p.) injection of L-arginine or omeprazole (each $3 \mathrm{mg} / \mathrm{kg}$ ). After administration of AmMs (30 or $150 \mathrm{mg} / \mathrm{kg}$, p.o.) to the AmMs-treated mice $(n=6)$, the animals were maintained in their cages for $1 \mathrm{~h}$ to allow metabolization. Individual cages were vertically immersed in a water bath (temperature exposure $21^{\circ} \mathrm{C}$ ) to the level of the xyphoid process. The mice were denied access to food or drink during the experiment. The mice were exposed for $6 \mathrm{~h}$ to WIRE stress and then euthanized with diethyl ether, and stomach tissues were extracted. Each tissue was engraved along the curvature, and the gastric mucosa was removed using a pair of anatomical scissors. The mucosal tissues were carefully examined for lesions at the glandular part of the surface. Blood was also gathered from the inferior vena cava of each mouse for blood analysis.

Determination of the ulcer index. Mucosal lesions were counted as previously reported (20). In brief, 1 point was assigned for small round hemorrhagic corrosions; 2 points were assigned when the length of the hemorrhagic corrosions was $<1 \mathrm{~mm}$; 3 points were assigned when the length was $1-2 \mathrm{~mm} ; 4$ points were assigned when the length was $2-3 \mathrm{~mm}$; and 5 points were assigned when the length was $>4 \mathrm{~mm}$. This score was then added and doubled when the width of the corrosions was $>1 \mathrm{~mm}$.

Reverse transcription-polymerase chain reaction analysis of $m R N A$ expression. Frozen gastric tissues $(100 \mathrm{mg})$ were normalized in $1 \mathrm{ml} \mathrm{TRIzol}{ }^{\circledR}$ reagent, and total RNA was arranged as previously described (21). The total RNA was measured using a spectrophotometer at $260 \mathrm{~nm}$ (VICTOR3; Perkin Elmer, Wellesley, MA, USA), and the RNA was quantified by $1 \%$ formaldehyde-agarose gel electrophoresis. The samples were then stored at $-80^{\circ} \mathrm{C}$ until use. Single-step RT-PCR was carried out by specific primer sets using the Maxime RT-PCR PreMix. These primers were constructed using the Primer3 software (Whitehead Institute, MIT Center for Genome Research, Cambridge, MA, USA) to evaluate sequences deposited in the NCBI GenBank database. The primers were synthesized by Bioneer Co. (Daejeon, Korea), as previously described (18). Briefly, first-strand cDNA was reverse-transcribed from $200 \mathrm{ng}$ of total RNA at $45^{\circ} \mathrm{C}$ for 


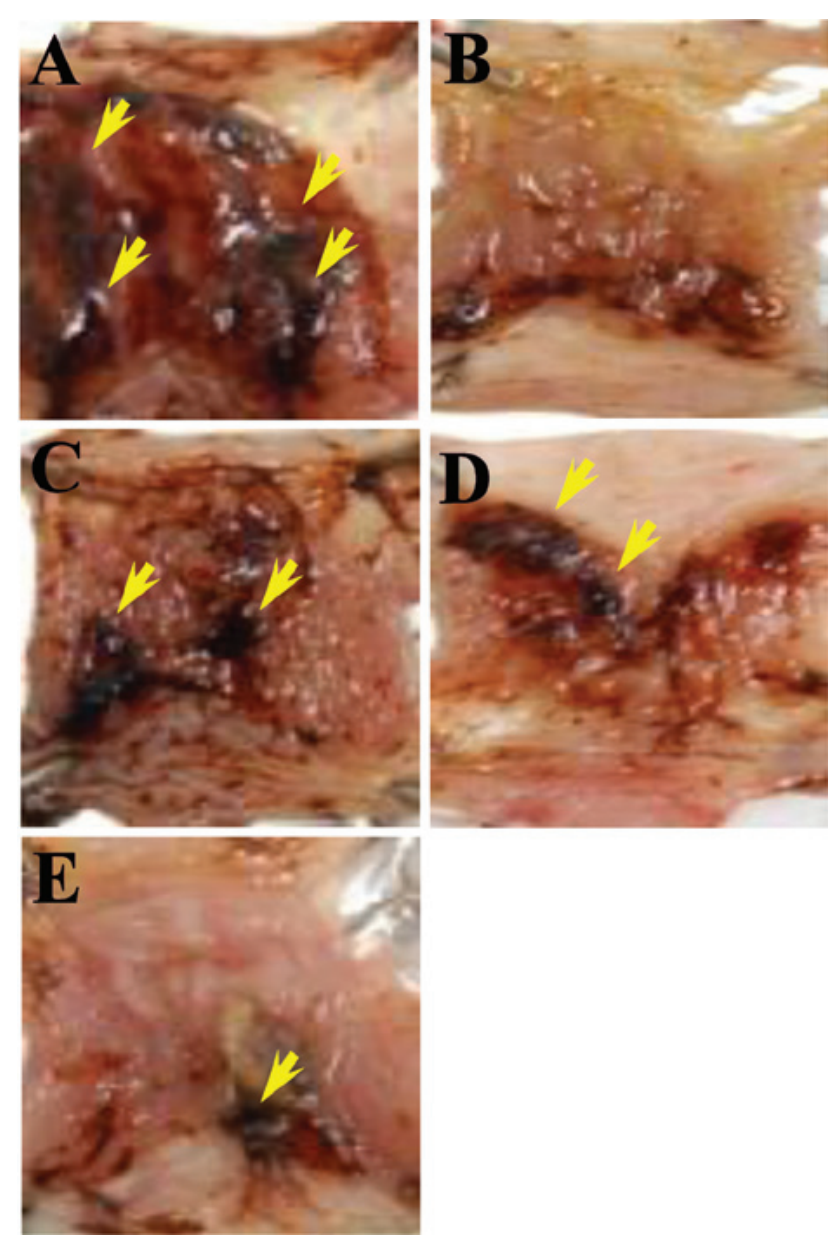

Figure 1. Gastroprotective effects of AmMs on WIRE stress-induced ulcer damage in mice. One hour prior to the initiation of WIRE stress, (A) control mice received a single saline administration p.o. $(0.02 \mathrm{ml})$; (B) positive control mice received a single dose of L-arginine $(300 \mathrm{mg} / \mathrm{kg}$ ) or (C) omeprazole $(300 \mathrm{mg} / \mathrm{kg}$ ); and (D and E) experimental mice received a single p.o. administration of AmMs (30 and $150 \mathrm{mg} / \mathrm{kg}$, respectively). After $6 \mathrm{~h}$ of exposure to water immersion, mice were euthanized and their stomach tissues were anatomized for damage. The images are representative of a set of classical examinations visualized under a microscope (Nikon ECLIPSE 90i; Tokyo, Japan). The arrows denote disrupted or intact forms of the ulcerative tissues as shown and scored according to the ulcer index (Fig. 2).

$30 \mathrm{~min}$; the samples were denatured for $5 \mathrm{~min}$ at $95^{\circ} \mathrm{C}$; and $\mathrm{PCR}$ amplification was executed with either 32 cycles (eNOS, nNOS and iNOS) or 27 cycles (18s RNA) of $45 \mathrm{sec}$ at $95^{\circ} \mathrm{C}, 45 \mathrm{sec}$ at $54^{\circ} \mathrm{C}$ for eNOS, $55^{\circ} \mathrm{C}$ for nNOS, $45 \mathrm{sec}$ at $53^{\circ} \mathrm{C}$ for iNOS and $60 \mathrm{sec}$ at $72^{\circ} \mathrm{C}$. Following the amplification process, $20 \mu \mathrm{l}$ of each RT-PCR product was determined by $1.5 \%$ agarose gel electrophoresis and visualized by EtBr staining. The position of the predicted product was verified by comparison to a $1-\mathrm{kb}$ DNA ladder (Solgent, Daejeon, Korea). The relative amounts of cDNA in each matched set were normalized with regard to $18 \mathrm{~s}$ RNA expression using the Molecular Imager Gel Doc XR System and Quantity One 1-D analysis software (Bio-Rad, Philadelphia, PA, USA).

Statistical analysis. Results were presented as the means \pm standard deviation (SD) of three independent values. Statistical significance was determined by the Student-Newman-Keuls method for independent means, using the Sigma Plot program

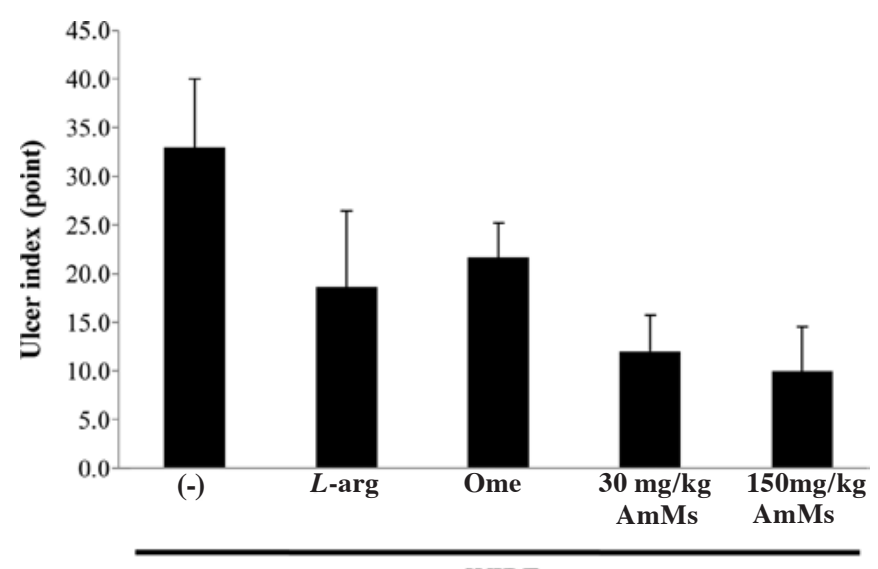

+ WIRE

Figure 2. Decrease in the ulcer index of WIRE stress-induced ulcer tissue samples from mice treated with AmMs. The ulcer index was calculated as described in Materials and methods. Data are presented as the means \pm SD (6 mice/group) of triplicate experiments by the Student-Newman-Keuls method for independent means, using the Sigma Plot. The critical level for significance was set at $\mathrm{p}<0.05 ; \mathrm{p}<0.05$ was considered significant.

(22). The critical level for significance was set at $\mathrm{p}<0.05$; $\mathrm{p}<0.05$ was considered statistically significant.

\section{Results}

Effect of AmMs on WIRE stress-induced gastric mucosal damage. One hour prior to the initiation of WIRE stress, negative control mice received a single saline administration p.o., whereas the positive control mice received a single i.p. injection of L-arginine $(300 \mathrm{mg} / \mathrm{kg})$ or p.o. administration of omeprazole (3 mg/kg). AmMs-treated mice received a single p.o. administration of AmMs (30 or $150 \mathrm{mg} / \mathrm{kg}$ ). After $6 \mathrm{~h}$ of WIRE-induced stress, all mice were euthanasized and their stomach tissues were examined for gastric injury, which was visualized as either disrupted or intact forms. In tissue samples from the stress-induced control, abundant lesions were observed, most often 1-2 mm in size (Fig. 1A). By contrast, tissue samples from the L-arginine- or omeprazole-treated mice presented very few lesions (Fig. 1B and C) while the stress-induced control group exhibited large-sized bloodcoagulating bunches (Fig. 1A). The positive control exhibited only small-sized bunches with minor lesions (Fig. 1B and C), which were not significant when compared to the stressinduced control. Regardless of the dose, AmMs-treated mice did not present any small- or large-sized corrosions (Fig. 1D and E; and data not shown). By counting mucosal lesions according to a previously described manner with a slight modification (20), the ulcer index was calculated as shown in Fig. 2. The ulcer index of the stress-induced control group was $23.0 \pm 4.1$, whereas the indices of the positive controls (L-arginine or omeprazole) were $8.0 \pm 5.5$ and $8.0 \pm 5.5$, respectively. Collectively, these findings reveal that AmMs protects against WIRE stress-induced gastric mucosal lesions in mice.

We next investigated how AmMs affects stress-induced ulcers in mice. Classically, most anti-ulcer effects involve the blockage of acid production on stomach epithelial cells during stress onset. Therefore, we determined whether the sap reduces the secretion of gastric acid. Treatment with sap slightly 


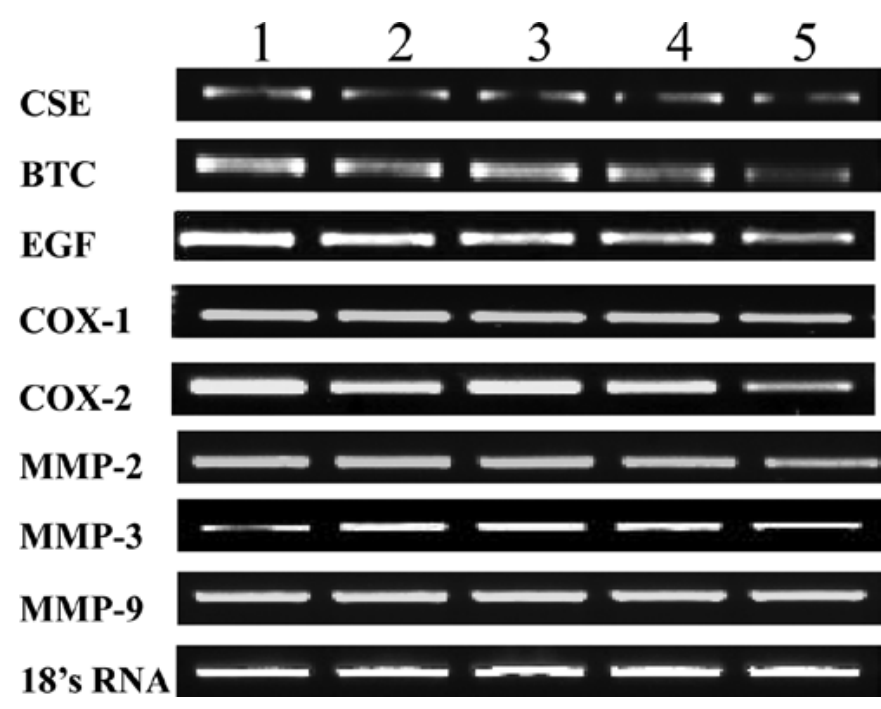

Figure 3. mRNA expression levels of various target proteins in AmMstreated ulcerative tissues. mRNA expression levels of CSE, BTC, EGF, COX-1, COX-2, MMP-2, MMP-3, MMP-9 and 18s rRNA are shown. Lane 1, control group; lane 2, L-arginine-treated group ( $300 \mathrm{mg} / \mathrm{kg}$, i.p.); lane 3, omeprazole-treated group ( $3 \mathrm{mg} / \mathrm{kg}$, i.p.); lanes 4 and 5 , AmMs-treated experimental groups (30 and $150 \mathrm{mg} / \mathrm{kg}$, p.o., respectively).

decreased the volume of $0.1 \mathrm{~N} \mathrm{NaOH}$, which is required to neutralize the gastric juice in the stomach, in a concentrationdependent manner (data not shown), while the total volume was reduced, but not dramatically, to $5.3 \%$. This revealed that the sap partially inhibits gastric secretion, indicating that other beneficial effects of AmMs exist.

Expression profiles of $m R N A$ of anti-inflammatory enzymes. We investigated whether the detected changes in serum and gastric tissue-derived enzyme levels were attributable to changes in the expression levels of inflammation-related enzymes. RT-PCR was used to scrutinize the mRNA expression levels of the genes encoding these anti-inflammatory enzymes, such as NOS and matrix metalloproteinases (MMPs). As shown in Fig. 3, the expression levels of CSE, BTC and EGF were not altered in the various mouse groups. Fold expression of cyclooxygenase- 1 and -2 and MMP-2, -3 and -9 were also not altered at the mRNA level, when compared to 18s RNA used as a control. Fig. 4A shows that the 305-bp gene product matching to iNOS cDNA was obviously reduced in ulcerative tissues from the WIRE-induced tissues, whereas the levels of the 307-bp eNOS band were similar to those of $18 \mathrm{~s}$ RNA, regardless of AmMs treatment. This fact was assessed by the relative band intensity of mRNA. As a result, we found that the iNOS gene product in the AmMs-treated $(150 \mathrm{mg} / \mathrm{kg}$ ) tissues was 5-fold lower than that of the tissues in the WIRE stress-induced group, while the iNOS gene product in the omeprazole-treated mice was decreased by 2 -fold (Fig. 4B). Notably, nNOS expression was dramatically decreased by treatment with $150 \mathrm{mg} / \mathrm{kg}$ AmMs when compared to the positive controls (Fig. 4A, third panel). This decrease in the nNOS mRNA expression was $\sim 30 \%$ when compared with the control, whereas the expression in the positive controls did not change (Fig. 4C; columns 1, 2 and 3 vs. 5). These results indicate that AmMs ameliorates gastric ulcers caused by the stress-induced

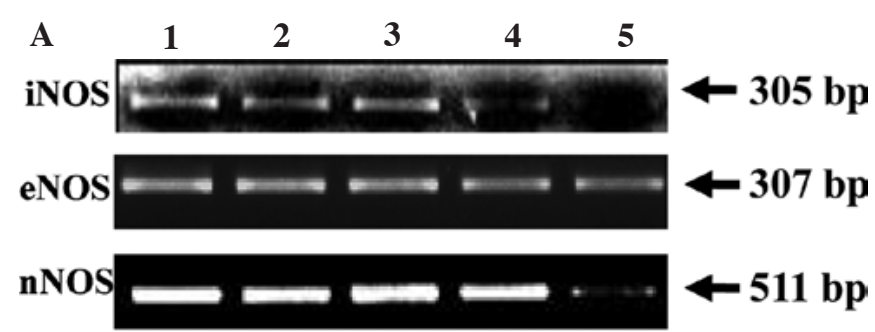

B

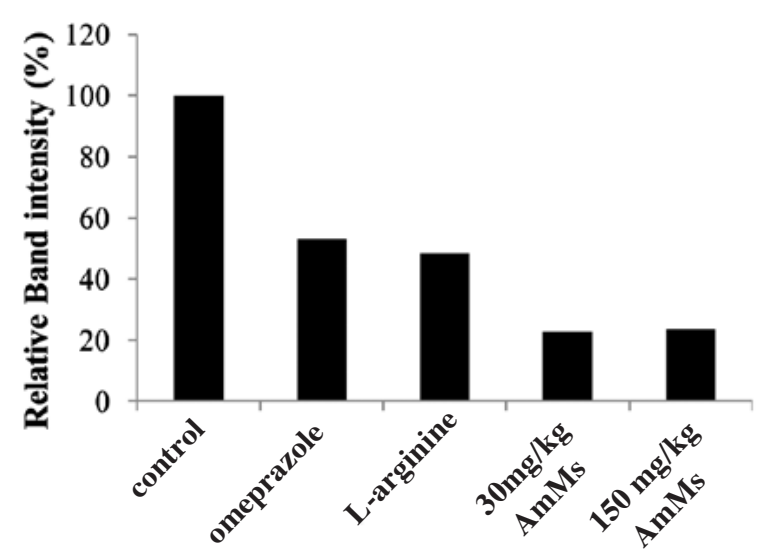

C

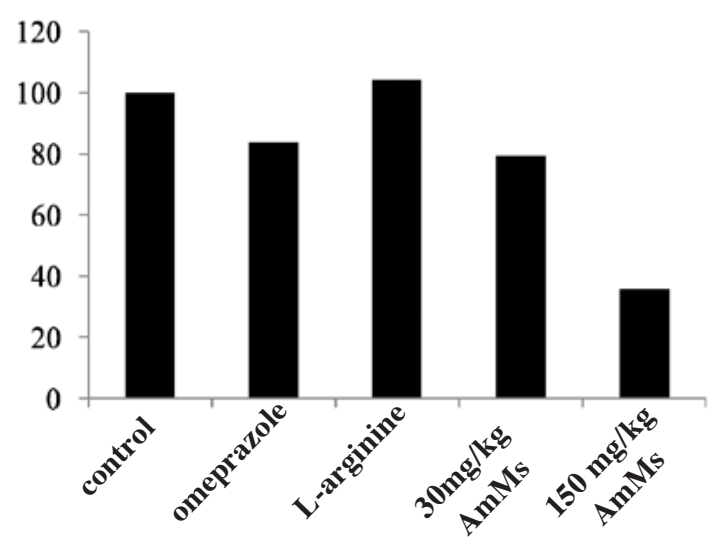

Figure 4. Comparison of the mRNA expression levels of NOSs. (A) The expression levels of iNOS, eNOS and nNOS mRNA were normalized with that of 18s rRNA, using Quantity One Version 4.6.1. One hour prior to the start of WIRE-induced stress, control mice received a single saline administration p.o.; positive control mice received a single i.p. injection of L-arginine $(300 \mathrm{mg} / \mathrm{kg})$ or omeprazole $(300 \mathrm{mg} / \mathrm{kg})$; and experimental mice received a single p.o. administration of AmMs (30 and $150 \mathrm{mg} / \mathrm{kg}$ ). Lane 1, control group; lane 2, omeprazole-treated group ( $3 \mathrm{mg} / \mathrm{kg}$, i.p.); lane 3, L-argininetreated group (300 mg/kg, i.p.); lanes 4 and 5, AmMs-treated experimental groups (30 and $150 \mathrm{mg} / \mathrm{kg}$, p.o., respectively). Relative band intensity (\%) of (B) iNOS and (C) nNOS comparing the expression levels in the various treatment groups. The data are the representative results of three independent experiments.

WIRE model via a decrease in nNOS as well as iNOS mRNA expression.

\section{Discussion}

In the present study, we report for the first time that treatment with AmMs safeguards against WIRE stress-induced gastric mucosal injury in mice (Figs. 1 and 2). This finding suggests that AmMs can be used as an ulcer remedy or for other preventive and nutraceutical purposes. 
Previous studies have revealed that WIRE stress-induced gastric mucosal damage involves increased gastric juice secretion, gastric peristalsis, gastrocirculation disturbances in mucosal tissues, reduced prostaglandin levels, low turnover of gastric mucosa and NO-induced changes in gastric mucus cells (23-25). Among these patterns, NO-mediated regulation is particularly important as it is associated with host defense and inflammatory responses (26) and also plays a pivotal role in gastric mucosal protection against damage induced by ethanol, stress, endotoxins and drugs (27). NOS activity is particularly high in gastric tissues (28), where NO helps maintain gastric tissue integrity (29), controls gastromucosal-derived blood flow (30) and increases gastric mucus synthesis and secretion (28). L-arginine, a NOS substrate, has been shown to facilitate gastric ulcer healing by increasing cell regeneration in stomach tissues (31). In addition, inhibition of NOS activity has been shown to intensify the stimulatory effects of NO on gastric mucus synthesis and secretion, to inhibit angiogenesis and to suppress ulcer healing $(10,32)$.

In the present study, we demonstrated several gastoprotective mechanisms against gastric ulceration as induced by WIRE-stress mucosal damage. We initially determined whether the sap inhibits gastric acid secretion. The results revealed that the gastric acid was neutralized only to $5.3 \%$ with AmMs treatment at a concentration of $20 \mu \mathrm{g} / \mathrm{ml}$ (data not shown). AmMs-treated mice exposed to WIRE-induced stress had decreased serum and NO contents in their stomach tissues when compared to the control stressed mice. Similar results were obtained in the L-arginine-treated mice, which were used as a positive control based on a previous report that L-arginine treatment prohibits the development of stressinduced gastric lesions (31). To analyze a feasible mechanism causing a decrease in NO content, we examined the expression levels of different NOS mRNAs. Our results showed that the gastric mucosal expression of iNOS and nNOS mRNA was significantly lower in the AmMs-treated mice vs. the control mice, whereas no such difference was observed in eNOS mRNA expression levels (Figs. 3 and 4). Together these findings indicate that the protective effects of NOS against WIRE stress-induced gastric lesions in vivo may originate, at least in part, from the suppression of NO signaling via decreased iNOS and nNOS mRNA expression by AmMs.

Previous studies suggest that the significance of constitutive NOSs in sustaining healthy gastric tissues is important as these enzymes are prevalent in all types of tissues. Decreased cNOS activity has been involved in gastric lesions, while accelerated cNOS mRNA expression, activity and immunoreactivity has been observed in the healing of gastric mucosa, particularly in newly formed vessels and neurons (33). Consistent with the knowledge that eNOS and nNOS are critical factors during the gastric tissue repair process, a cigarette smoking-mediated decrease in gastromucosal NOS activity was found to be related to reduced gastric blood flow and inhibition of cell regeneration in ulcerative tissues (10); however, no changes were observed in eNOS mRNA expression in the AmMs-treated mice exposed to WIRE-induced stress (data not shown). Instead, changes were detected in the mRNA expression levels of iNOS, suggesting that this isoform of NOS may be involved in the mechanism of AmMs-induced protection in ulcer tissues.
Large amounts of iNOS-induced NO have been identified in gastric tissue damage during inflammatory processes (34), and high levels of iNOS expression and activity have been related to severe inflammation in ulcerative mucosal cells (35). Studies have revealed that iNOS is usually induced under oxidative reactions, wherein high levels of NO reacts with the superoxide anion, thus causing peroxynitrite generation, tyrosine-mediated nitration, hydroxyl radical production, cellular toxicity and tissue lesions $(35,36)$. In the present study, we found high levels of iNOS mRNA expression in gastric mucosal lesions in the control mice, but significantly lower levels in the AmMs-treated mice, indicating that nutritional factors of AmMs may diminish NO production by preventing iNOS expression in WIRE-induced stress conditions. This may then inhibit the abundant release of attacking NO, leading to beneficial anti-ulcer effects.

In summary, we prove here for the first time that exogenously administered AmMs protects against the development of WIRE stress-induced gastric mucosal lesions in mice, and that this protective effect may be attributable to decreased iNOS/nNOS mRNA expression and subsequent decreases in damaging NO levels. Although future studies are required to elucidate the specific mechanisms of this protective effect, these novel findings suggest a new mode of action for AmMs, and may imply that the sap of this traditional tree can be developed for future use in ulcer prevention.

\section{Acknowledgements}

This study was supported, in part, by the Kyungpook National University Research Fund. The authors would like to thank Mr. Sung-Gu Ji and Mr. Hae-Hee Yoon (JukJang Acer Agricultural Cooperative) for the technical assistance of the AmMs collection.

\section{References}

1. MacLaren R, Jarvis CL and Fish DN: Use of enteral nutrition for stress ulcer prophylaxis. Ann Pharmacother 35: 1614-1623, 2001.

2. Mózsik G, Bódis B, Figler M, Király A, Karádi O, Pár A, Rumi G, Sütõ G, Tóth G and Vincze A: Mechanisms of action of retinoids in gastrointestinal mucosal protection in animals, human healthy subjects and patients. Life Sci 69: 3103-3112, 2001.

3. Alarcón de la Lastra C, Barranco MD, Motilva V and Herrerías JM: Mediterranean diet and health: biological importance of olive oil. Curr Pharm Des 7: 933-950, 2001.

4. Konturek SJ, Konturek PC and Brzozowski T: Melatonin in gastroprotection against stress-induced acute gastric lesions and in healing of chronic gastric ulcers. J Physiol Pharmacol 57 (Suppl 5): 51-66, 2006.

5. Pawlik M, Ptak A, Pajdo R, Konturek PC, Brzozowski T and Konturek SJ: Sensory nerves and calcitonin gene-related peptide in the effect of ischemic preconditioning on acute and chronic gastric lesions induced by ischemia-reperfusion. J Physiol Pharmacol 52: 569-581, 2001.

6. Kwiecieñ S, Brzozowski T, Konturek PC, Konturek SJ, Pawlik M, Pajdo R, Drozdowicz D, Ptak A and Hahn EG: Effect of central and peripheral actions of histamine and its metabolite $\mathrm{N}$-alpha methyl histamine on gastric secretion and acute gastric lesions. J Physiol Pharmacol 52: 625-638, 2001.

7. Nishida K, Harrison DG, Navas JP, Fisher AA, Dockery SP, Uematsu M, Nerem RM, Alexander RW and Murphy TJ: Molecular cloning and characterization of the constitutive bovine aortic endothelial cell nitric oxide synthase. J Clin Invest 90: 2092-2096, 1992. 
8. Moncada S, Higgs EA and Furchgott R: International union of pharmacology nomenclature in nitric oxide research. Pharmacol Rev 49: 137-142, 1997.

9. Anggard E: Nitric oxide: mediator, murderer, and medicine. Lancet 343: 1199-1206, 1994.

10. Ma L, Chow JY and Cho CH: Cigarette smoking delays ulcer healing: role of constitutive nitric oxide synthase in rat stomach. Am J Physiol 276: 238-248, 1999.

11. La Vecchia $\mathrm{C}$ and Tavani A: A review of epidemiological studies on cancer in relation to the use of anti-ulcer drugs. Eur J Cancer Prev 11: 117-123, 2002.

12. Schmeda-Hirschmann G and Yesilada E: Traditional medicine and gastroprotective crude drugs. J Ethnopharmacol 100: 61-66, 2005 .

13. Lee GS, Byun HS, Kim MH, Lee BM, Ko SH, Jung EM, Gwak KS, Choi IG, Kang HY, Jo HJ, Lee HJ and Jeung EB: The beneficial effect of the sap of Acer mono in an animal with lowcalcium diet-induced osteoporosis-like symptoms. Br J Nutr 100: 1011-1018, 2008

14. Yang H, Lee MK and Kim YC: Protective activities of stilbene glycosides from Acer mono leaves against $\mathrm{H} 2 \mathrm{O} 2$-induced oxidative damage in primary cultured rat hepatocytes. J Agric Food Chem 53: 4182-4186, 2005

15. Yang H, Sung SH and Kim YC: Two new hepatoprotective stilbene glycosides from Acer mono leaves. J Nat Prod 68 101-103, 2005

16. Heo JC, Rho JR, Kim TH, Kim SY and Lee SH: An aqueous extract of green tea Camellia sinensis increases expression of Th1 cell-specific anti-asthmatic markers. Int J Mol Med 22: 763-767, 2008

17. Zimmermann M: Ethical guidelines for investigations of experimental pain in conscious animals. Pain 16: 109-110, 1983.

18. An SM, Park CH, Heo JC, Park JY, Woo SW, Seo JH, Lee MS, Cho KJ, Cho HS, Shin HM and Lee S-H: Gastrodia elata Blume protects against stress-induced gastric mucosal lesions in mice. Int J Mol Med 20: 209-215, 2007.

19. Naesdal J, Bodemar G and Walan A: Effect of omeprazole, a substituted benzimidazole, on 24-h intragastric acidity in patients with peptic ulcer disease. Scand J Gastroenterol 19: 916-922, 1984.

20. Nie SN, Qian XM, Wu XH, Yang SY, Tang WJ, Xu BH, Huang F, Lin X, Sun DY, Sun HC and Li ZS: Role of TFF in healing of stress-induced gastric lesions. World J Gastroenterol 9 : $1772-1776,2003$

21. Roos-van Groningen MC, Eikmans M, Baelde HJ, de Heer E and Bruijn JA: Improvement of extraction and processing of RNA from renal biopsies. Kidney Int 65: 97-105, 2004

22. Falkeholm L, Grant CA, Magnusson A and Moller E: Xylene-free method for histological preparation: a multicentre evaluation. Lab Invest 81: 1213-1221, 2001.

23. Kitagawa H, Fujiwara M and Osumi Y: Effects of water-immersion stress on gastric secretion and mucosal blood flow in rats. Gastroenterology 77: 298-302, 1979.
24. Garrick T, Leung FW, Buack S, Hirabayashi K and Guth PH: Gastric motility is stimulated but overall blood flow is unaffected during cold restraint in the rat. Gastroenterology 91: 141-148, 1968.

25. Lamarque D and Whittle BJ: Involvement of superoxide and xanthine oxidase in neutrophil-independent rat gastric damage induced by NO donors. Br J Pharmacol 116: 1843-1848, 1995

26. Calatayud S, Barrachina D and Esplugues JV: Nitric oxide: relation to integrity, injury, and healing of the gastric mucosa. Microsc Res Tech 53: 325-335, 2001.

27. Nishida K, Ohta Y and Ishiguro I: Role of gastric mucosal constitutive and inducible nitric oxide synthases in the development of stress-induced gastric mucosal lesions in rats. Biochem Biophys Res Commun 236: 275-279, 1997.

28. Brown JF, Hanson PJ and Whittle BJ: Nitric oxide donors increase mucus gel thickness in rat stomach. Eur J Pharmacol 223: 103-104, 1992.

29. Whittle BJ, Lopez-Belmonte J and Moncada S: Regulation of gastric mucosal integrity by endogenous nitric oxide: interactions with prostanoids and sensory neuropeptides in the rat. Br J Pharmacol 99: 607-611, 1990.

30. Pique JM, Esplugues JV and Whittle BJ: Endogenous nitric oxide as a mediator of gastric mucosal vasodilatation during acid secretion. Gastroenterology 102: 168-174, 1992

31. Brzozowski T, Konturek SJ, Sliwowski Z, Drozdowicz D, Zaczek M and Kedra D: Role of L-arginine, a substrate for nitric oxide-synthase, in gastroprotection and ulcer healing. J Gastroenterol 32: 442-452, 1997.

32. Konturek SJ, Brzozowski T, Majka J, Pytko-Polonczyk J and Stachura J: Inhibition of nitric oxide synthase delays healing of chronic gastric ulcers. Eur J Pharmacol 239: 215-217, 1993.

33. Brzozowski T, Konturek PC, Konturek SJ,Pajdo R, Drozdowicz D, Kwiecien S and Hahn EG: Acceleration of ulcer healing by cholecystokinin (CCK): role of CCK-A receptors, somatostatin, nitric oxide and sensory nerves. Regul Pept 82: 19-33, 1999.

34. Barrachina MD, Panes J and Esplugues JV: Role of nitric oxide in gastrointestinal inflammatory and ulcerative diseases: Perspective for drug development. Curr Pharm Des 7: 31-48, 2001.

35. Kankuri E, Vaali K, Knowles RG, Lahde M, Korpela R, Vapaatalo H and Moilanen E: Suppression of acute experimental colitis by a highly selective inducible nitric-oxide synthase inhibitor, N-[3-(aminomethyl)benzyl]acetamidine. J Pharmacol Exp Ther 298: 1128-1132, 2001.

36. Ding HL, Zhu HF, Dong JW, Zhu WZ, Yang WW, Yang HT and Zhou ZN: Inducible nitric oxide synthase contributes to intermittent hypoxia against ischemia/reperfusion injury. Acta Pharmacol Sin 26: 315-322, 2005. 